\title{
The Research of University Campus Culture Construction in the New Period
}

\author{
Hui Shang \\ School of Food Science and Engineering, Nanjing University of Finance \& Economics, Nanjing \\ 210023, China. \\ sh8506@126.com
}

Keywords: New period, university, campus culture construction, characteristic.

\begin{abstract}
Along with the rapid growth of social economy, the state pays more attention to higher education and invests a lot of funds to build the infrastructure, which effectively promotes the further development of higher education. At the same time, universities are gradually connected with society in many aspects. Under this background, the construction of university campus culture is facing new challenges. How to build a healthy campus culture in the new period and how to encourage teachers and students to participate in the construction have attracted many scholars to study. This paper describes the characteristics of university campus culture construction in the new period, analyzes the problems arising in the process of construction and finally puts forward corresponding solutions to promote the construction of university campus culture.
\end{abstract}

\section{Introduction}

Campus culture is defined as the sum of all the cultural phenomena occurring in the campus, in which the members of campus life are the main body, the extracurricular cultural activities are the main content and the campus is the main space. As part of the modern socialist spiritual civilization construction, it is necessary for universities to recognize the importance of campus culture construction and put into action in order to cultivate the talents that society really needs. In recent years, the rapid development of social economy has proposed higher requirements for the talents graduated from universities, such as professional theoretical knowledge and practical ability. As a group culture, the university campus culture construction is directly related to the direction of training talents in universities. At present, the construction of university campus culture is frustrated influenced by many factors. For those reasons, this paper deeply considers the university campus culture construction in the new period, which is of great importance. In the new period, the construction of university campus culture has two characteristics descripted as follows:

First, campus cultural activities become more commercial. The biggest influence of market economy on the university campus culture is that any activity is measured by the market value, and the guiding function of spiritual value of the campus culture cannot fully play its role. In recent years, the university campus spirit has gradually mutated in a covert manner, and has begun to chase the utilitarian of short-term behavior. Some practical market values directly seduce university students, resulting in the inability to form the correct three views [1]. Under this background, the university campus culture gradually crosses the high walls, constantly seeks the fitting point with social forms, and continuously integrates with the market economy. At the same time, the construction of university campus culture needs a clear orientation to open up a new path for the innovation of university campus culture [2]. It is necessary to comprehensively consider the actual situation and specific functions of universities and avoid losing the existing functions when positioning. Only in this way can universities achieve sustainable development and maintain the original function.

Second, campus culture and social culture lose their balance. Nowadays, there is a one-sided phenomenon in campus culture and social culture. The current mainstream of campus culture in universities is not the traditional "academic culture". Since the university culture has broken the barrier of the high wall and is integrated with market economy, students carry out various activities 
not only limited to the traditional cultural activities, but also multifarious cultural activities required for social and economic development, so as to establish close relationships for society [3]. With the further development of the market economy, social culture has gradually infiltrated into the campus, resulting in a gradual reduction in the influence of university campus culture and the continuous weakening of its radiation power for society [4]. At the same time, the social culture has made a great impact on the campus culture, such as the hot business heat and the hot stock. However, the campus culture is difficult to influence the society culture.

\section{Problems Generated in Campus Culture Construction under New Period}

In the context of rapid social and economic development, the university campus culture is gradually connected with the society, which brings a series of challenges for the construction of campus culture. Although universities are aware of the importance of campus culture construction in the new period, they have no effective solutions to solve the problems occurring in the construction due to a series of influencing factors. As a result, the formation of university campus culture is seriously affected, and the further development of universities is hindered to some extent.

\subsection{Lack of Clear Goals for Campus Culture Construction.}

Unclear goals and vague thinking are prominent issues in the construction of university campus at this stage. The main purpose of the campus culture construction in universities is to promote the school spirit, help students form the correct three views, and cultivate students' spirit, such as humanistic spirit, scientific spirit and innovative spirit [5]. However, in reality, the campus culture construction has followed the trend, which is blind and chaotic. In terms of functions such as education and innovation, it is difficult to make full use of existing functions. Nowadays, the value orientation of universities mainly focuses on science and technology, and looks down on humanities.

In the construction of university campus culture, the imperceptible influence of humanistic environment is often ignored or mistakenly understood by relevant personnel. For example, it is regarded as a part of moral education [6]. The lack of humanistic integration in the construction cannot bring out the existing functions of humanistic education, which consequently makes it difficult to effectively cultivate students' comprehensive quality. The talents that emerge from such cultivation methods often do not meet the actual needs of social development [7]. Moreover, once the construction of university campus culture is separated from science education, it will inevitably affect the cultivation of scientific spirit for university students. Then, the innovation of science and technology, and the further development of society will also be adversely affected.

Campus cultural life in universities is mainly reflected in the life culture. In the course of campus culture construction, once it is divorced from the life culture, that is, it deviates from the core. Even if the cultural activities are rich and colorful, it is hard to promote the students' spiritual growth. In addition, some of the campus cultural activities at this stage obviously focus on entertainment and ignore education, which causes the existing role of campus cultural activities to fail to play their part. In other words, placing particular emphasis on the diversity of physical culture and cultural methods will lead to ineffective development of campus spiritual culture and incomplete cultivation of students' spirit [8].

\subsection{Limitations of Campus Culture Construction.}

Nowadays, the functions and tasks of campus culture construction in most universities are mainly executed by student management departments. In other words, campus culture construction activities have become a way or means of business life for university students, and the control function and material function of campus culture are paid more attention. Specifically, the student management department often neglects the process of various activities, but lays emphasis on the results, and regards outcomes as the criteria for their own success. As a result, the educational value of cultural activities is overlooked during the whole university campus cultural activities. Secondly, there are many areas need to be improved in the university campus culture construction system, particularly some details. Thirdly, there is a lack of clear objectives, reasonable schemes, and scientific assessment mechanisms for the campus culture construction. 
In brief, the construction of university campus culture is unable to form a good campus cultural atmosphere for students, affected by the market economy and many other factors in the new period.

\section{Solutions for Campus Culture Construction under New Period}

Considering the existing problems, universities need to take measures from the following aspects.

\subsection{Enhancing Importance to the Positive Role of Popular Culture.}

All along, the ideological education in universities has been completed through a single, inculcate ideological and political education. With the development of information technology, the cultural exchanges between China and the West are becoming increasingly close, and the struggle in the ideological and political fields is very intense. Therefore, universities need to explore the innovative way of combining ideological education and university campus culture, give full play to the political function of campus culture and pay attention to the positive role of popular culture.

As a product of market economy, popular culture can embody the spirit of the times, reflect the social forms and adapt to social and economic development. However, popular culture also has a huge impact on mainstream ideology. In this context, consolidating the dominant position of social ideology is high on the agenda. Say concretely, to rationally guide the development of popular culture, abandon some dross factors, and build a cultural system dominated by mainstream culture and coexist with other cultures. It is worth noting that the construction requires campus culture as the dominance, and combining with social culture, in order to enrich the campus culture.

\subsection{Paying Attention to the Guiding Role of Socialist Core Values.}

University campus culture has the characteristic of diversification, but it does not mean that the development of different cultures is consistent. Similarly, the existence of multiculturalism does not mean that the public recognizes all cultures. Hence, the campus culture construction should clear the value orientation, and take the road of persisting in mainstream culture as the dominant and multicultural coexistence. The establishment of a socialist advanced cultural system in the new period is mainly based on two aspects. (1) Adhering to the dominant position of Marxism and being consistent with the direction of social development in terms of ideology and development direction;

(2) Cultivating successors of socialist career and pushing on the inheritance and innovation of culture.

\subsection{Strengthening the Construction of Related System.}

The construction of university campus culture needs support from related systems. More specifically, school committees, school students' unions and other organizations should be assigned to take charge of the university campus culture construction, to ensure that the university campus culture conforms to the spirit of campus culture and the construction work processes smoothly. In addition, corresponding regulations should be formulated based on the actual situation and all teachers and students should be encouraged to participate in the campus culture construction. Only through full participation can the university campus culture construction be further promoted. What's more, the ideological and political education department ought to actively cooperate with the participants and grasp the development direction of the campus culture construction.

\section{Conclusion}

In summary, under the background of rapid social and economic development, the university campus culture construction is impacted by the market economy and the influence of campus culture is weakened to some degree. Therefore, it is necessary for universities to highly recognize the problems occurring in the construction, and carry out the campus culture construction from the aspects of focusing on the positive role of popular culture, paying attention to the guiding role of the socialist core values, and strengthening the construction of related system.

Acknowledgment: The research is supported by the Top-notch Academic Programs Project of Jiangsu Higher Education Institutions (Grant No. PPZY2015B152), the Priority Academic Program Development of Jiangsu Higher Education Institutions (Grant No. PAPD). 


\section{References}

[1]. Xiuhong Cheng. Problems and Countermeasures of the University Campus Culture Construction in the New Period [J].Education for Chinese After-school, 2016(05):59-60.

[2]. Xiaoping Tina. Study on University Culture Construction for Promoting the High-level Development of Lang fang [J]. Journal of North China Institute of Aerospace Engineering, 2015, 25(06):41-44.

[3]. Guerin Pei. A Review of Researches on University Cultural Education in the New Period [J].Social Sciences Journal of Universities in Shanxi, 2015, 27(04):80-84.

[4]. Kailua Liu, Ting Liu, Dilixiati·kadier. The Research of University Campus Culture Construction in the New Period [J].Modern SOE Research, 2015(06):246.

[5]. Qigong Tina, Qi and Kong. Inheriting Chinese Excellent Traditional Culture and Promoting Socialist Core Values in the University Campus Culture Construction in the New Period [J]. Film Review, 2014(Z1):111-112.

[6]. Shang Li. A Review of the Relationship Between University Cultural Construction and Moral Cultivation [J]. The Guide of Science \& Education (First Issue), 2014(04):1-2+80.

[7]. Jintao Li, Xiangming Luo. Theory and Countermeasures of the University Campus Culture Construction in the New Period [J].Human Social Sciences, 2013(04):235-237.

[8]. Zaidi Liu, Hating Wang. On the Role of University Students' Legal Aid in the Construction of University Campus Culture in the New Period [J].Ideological and Political Education Research, 2013, 29(03):117-119. 